\title{
AN INTERCULTURAL SENSITIVITY AS A PROFESSIONAL TRAIT OF SPECIALISTS OF HUMANITARIAN SPHERE
}

\author{
Lyudmila Pochebut \\ St. Petersburg State University, Russia \\ Yuliya Logashenko \\ Immanuel Kant Baltic Federal University \\ Kaliningrad, Russia
}

\begin{abstract}
This paper is discussing the place of intercultural sensitivity in the structure of the intercultural competence. Here a role of intercultural sensitivity between different professional traits of humanitarian sphere's specialist and their bond with each other are discussing. We suppose that developed intercultural sensitivity helps to the specialist to be more professional in his/her work because it lets him or her to answer the question "Do the person's problems associated with his/her culture or not?» Sometimes it could be very important because we use other methods and approaches if the answer is «Yes».

In this paper the empirical investigation results. The sample includes students of Immanuel Kant Baltic Federal University (Kaliningrad, Russia) of different humanitarian specialties.
\end{abstract}

Keywords: intercultural competence, intercultural sensitivity, the specialties of the social sphere.

\section{Introduction}

There is no any country today, perhaps, which could avoid a clash with migrant processes. More and more people, belonging to different ethnical cultures, remove to another countries looking for «better life». All of them bump into stranger culture. All of them become involved to the acculturation process, going through not always good experience. In this case a professional help would be very opportunely. For many countries migration is really big problem: rising of crime and unemployment, reduction of jobs, ethnic conflicts, educational troubles in schools and others. Not each country has special programs for stabilization of situation in this field because it relates not only with substantial financial charge but with realization of depth and measuring of future changes. We know about experience of USA, Germany, Italy, Denmark and several another states at deciding of questions relating with migration. In any case for effective deciding of such questions are necessary people who know and are able to communicate on a professional level with migrants bearer of another culture. They are people who can to perceive, understand, and remember and to structure information due to cultural characteristics of other people or groups. There are many professionals who have to interact with migrants or tourists each day. To be interculturally competent is very important for them. But, is it possible to be so without intercultural sensitivity? We are sure it is no possible.

The aims of our study were:

1. to measure the level of intercultural sensitivity of experimental and control samples and to compare them; 
2. to test the link between intercultural sensitivity and several socialpsychological traits such as a locus of control, tolerance, ethnic identity.

The main method of our investigation is testing. Data of testing was verified with correlation analysis (by Pearson's r).

\section{Methodology}

In this paper we are going to consider two approaches to the intercultural competence and sensitivity. The first one is a conception of Milton Bennett which are known as «Developmental Model of Intercultural Sensitivity (DMIS)».

A developmental model of intercultural sensitivity was created by Bennett for explaining of varied reactions of people to similar experiences causing it with cultural difference. According the model, intercultural understanding not innate and could be studied. The next point of conception suggests that people and cultures are dynamic and highly differentiated. And, the third position is that intercultural competence is not an "objective knowledge" (e.g., knowledge gained through studying a particular culture's history) but represents a "phenomenological knowledge", which comes to person with his/her individual experience and helps him/her to develop skills for interpreting and understanding of direct intercultural interactions.

DMIS is positioned as a model of intercultural communicative competence (Matsumoto, 2008). According to the model of Bennett, the intercultural sensitivity of the individual passes the six stages of development from the moment of collision with another culture (Bennett, 1993). The first three stages (avoidance, protection, Minimization) describe the ethnocentric stage of development, the other three (acceptance, adaptation, integration) ethnorelativism stage. Under the ethnocentrism in the science (cultural anthropology) they understand a series of ideas about their own ethnic community and its culture as a central principal in relation to others. Typically, this role belongs to the native culture. Relativity puts the focus on diversity and differences of cultures, forms of knowledge, conceptual schemes, theories, and values. (Oxford Dictionaries, 2014).

Bennett affirms that each stage corresponds with learning steps for moving toward greater relativity. The reverse is also true: if a person is bad prepared for a particular experience associated with more developed intercultural stage, he/she may move in a negative direction. For example, to protect himself through the cultural superiority a person may to react negatively to ideas of cultural ethnorelativity, while they would be appropriate for someone in the minimization stage. Based on the model of Bennett, the most preferred is the situation when people living in a particular territory, have intercultural sensitivity by level of ethnorelyativism.

As a theory of Pochebut Lyudmila argues, intercultural competence is a psychological prerequisite for a constructive interaction between bearers of 
different cultures. Communicative competence is a person's skill for provide an appropriate reactions to a variety of problems arising in the process of communicating with other people. Communicative competence is a system of knowledge about social reality and about him. It is about complex social interaction skills helping to adapt to new situations. The quality of result of interaction is a criterion of development of communicative competence: if a person could to achieve meaningful goals for him without losses of another side, it points to sufficiently high level of developing. (Pochebut, 2012).

Intercultural competence characterized by respect, tolerance and trust, knowledge of principles and rules of intercultural communication, the skill to understand and interact with different cultures. Formation of intercultural competence implies the acquisition of knowledge about own and other cultures (language, history, art, literature, architecture, mythology and folklore, religion, etc.). However, it is not enough to know cultural characteristics, each person also must to develop of skills, experience, specific skills for communicate with other people and cultures. The structure of intercultural communicative competence includes the following components.

1. Knowledge of a culture: deep knowledge of their own culture, familiarity with the cultures of other countries.

2. Competencies and abilities of interaction not only with their own, but also with other cultures.

3. The particular relationship with people: tolerance and interest in the situation of communication with preserving their own identity and resistance to influence from the representatives of other cultures.

4. Social and psychological sensitivity - sensitivity to the states and feelings of others, empathic skills.

5. Trust to the people, the lack of bias and prejudice, ethnocentrism and xenophobia.

6. Commitment to the cultural approved norms of interaction, absence of discrimination against members of another culture.

In addition, for successful intercultural interaction, the psychological readiness of person is necessary, which is due to its level of communicative competence and tolerance. In addition to the manifestations of tolerance and trust, people must to have particularly sensitivity in establishing and maintaining crosscultural contacts (Pochebut, 2010). She speaks about social-psychological sensitivity and, as about its component, the intercultural sensitivity, which she defines as «an attentiveness of person to the cultural differences, evaluation of them from positions of relativity, a skill to understand and take part of plurality of ideas, valuations and attitudes».

In our study, the intercultural sensitivity is understood as an ability of a person to perceive, understand, remember and to structure cultural characteristics of other people or groups, based on which to predict their behavior and activities (Logashenko, 2010). 
In the study we have chosen several social-psychological characteristics which, as we think, are important for professional of social sphere and are related with intercultural sensitivity - locus of control, tolerance, ethnic identity. Why these?

The concept of locus of control was worked out by Julian Rotter, American psychologist. The scientist had developed a range of internal and external locus of control, in order to determine the degree of control over reinforcements. People of one type - "internals" - are characterized by high level of responsibility; they are looking for reasons of external events inside themselves. They are attentive to their own feelings and inclined to reflection.

Another type of people, "externals", looking for reasons of different events outside: in other people, in fate, in the circumstances. They attach a great importance to the external attributes of the situation and have fewer tendencies to reflection. Locus of control is one of significant indicator which could forecast a person's behavior. We suppose, the locus of control is very important for development of intercultural sensitivity. Theoretically, people with internal locus of control people with internal locus of control should be more sensitive to the propensity for self-reflection, higher responsibility, that helps to realize and accept own cultural traits and, through that, - cultural traits of a partner by communication, and also to assume some of the responsibility for the process and result of interaction.

Tolerance and intercultural sensitivity are related concepts because reflect an readiness to accept differences in other person. "Tolerance is the respect of the rights of another person, provided that he also respects your rights, it is freedom from bias, prejudice and discrimination" (Pochebut, 2012). As Lebedeva Nadezhda has wrote, ethnic tolerance are characterized by presence of positive image of other culture's representative together with the positive image of own culture. It is mean, that ethnic tolerance isn't a consequence of acculturation as a disavowal from the own culture, but is a trait of interethnic integration, which characterized by "acceptance" or positive attitude to the own ethnic culture and to the ethnic cultures of groups of contact. There are several factors, affecting on the ethnic tolerance:

1. extent of ethnocultural competence,

2. psychological preparedness for multicultural dialogue,

3. experience and skills of intercultural perception and interaction.

All these parameters could be formed and developed for what they can use education and social-psychological training of intercultural competence. (Lebedeva, 2011)

We supposed that tolerance and intercultural sensitivity relate to each other and tested it in our study. An ethnic identity is a person's characteristic, defining his/her confidence in a social space. Realizing his/her own place in the referent ethnic group a person could feel self more stable, feel a support from this group, even if it is not really. Emotional background matters in any case because 
positive identity bear up a person in the intercultural contact helps to use it as resource, raising up his/her self-appraisal. On the contrary, negative identity becoming a barrier on the way of good intercultural dialogue.

The hypotheses of our study were the next suppositions:

1. The intercultural sensitivity of respondents has developed on the middle level;

2. There are connections between an intercultural sensitivity, a locus of control, a tolerance and an ethnic identity;

3. The quality of these connections is different.

\section{Study}

The study involved students of specialties: "low", "psychology", "sociology", "journalist" and "linguistic" from Immanuel Kant Baltic Federal University (Table 1). Students of these specialties are focused on interpersonal interaction teaching, counseling, social work and helping people in difficult situations regardless of ethnic and cultural affiliation of its clients or colleagues. Graduates should have a range of professional competences including the intercultural communicative competence.

Table 1

Sample characteristics

\begin{tabular}{|c|c|c|c|}
\hline \multirow{2}{*}{ Specialty } & \multirow{2}{*}{ Quantity } & \multicolumn{2}{|c|}{ Sex } \\
\cline { 3 - 4 } & & Male & Female \\
\hline "low", & 17 & 6 & 15 \\
\hline "psychology", & 9 & 1 & 8 \\
\hline "sociology" & 10 & 5 & 5 \\
\hline "journalism and linguistics" & 12 & 2 & 4 \\
\hline "economics"(management) & 10 & 6 & 38 \\
\hline TOTAL & 58 & 20 & 10 \\
\hline
\end{tabular}

To test this hypothesis, we used the method of study of intercultural sensitivity, the proposed Khukhlaev O. and Chibisova M. (Chibisova \& Khukhlaev, 2008). The technique includes 51 affirmations. Each statement respondents must to assess on scale from 0 to 10 . Respondent's answers are calculated based on the key. The technique consists of 4 scales. The scale 1 - the acceptance - refers to the ethnorelativism stage of development of intercultural sensitivity by M. Bennett. The scale 2 - the Minimization - refers to the ethnocentric stage of development of intercultural sensitivity. Scale 3 - the absolutization- also refers to the ethnocentric stage. Scale 4 - the ambivalence- represents a transitional stage between the ethnocentric and etnorelativistic stages.

The tolerance was tested with method " Intolerance - tolerance" (INTOL) which was worked out by Ludmila Pochebut (Pochebut, 2012). This method was 
constructed according to a procedure of Likert Scale and it is used a measuring the tolerance of person. "INTOL" define a ratio between intolerance and tolerance of a person. The technique includes two scales - "tolerance" and "intolerance", - and 16 statements, which must be evaluated by the respondent, using a scale from "-2" to "+2". Maximum summary by the scale "tolerance" equals +16 marks, maximum summary by the scale "intolerance" equals -16 marks. Maximum index INTOL equals +32 marks, minimum index INTOL equals - 32 marks. In norm, values should be varying between -12 and +12 marks.

A technique of measuring of ethnic identity was worked out by Olga Romanova (Romanova, 1994). This technique lets to measure self-identification through knowing the peculiarities of the own ethnic group and subjective meaning of the membership in this ethnic group for a person. There are 21 statements which must be evaluated by the respondent, using a scale from "totally agree" to "strongly disagree". A level of ethnic identity is clarify by three indicators producing in a key. Three indicators presenting by O. Romanova are:

1. A sense of belonging to the own ethnic group,

2. A significance of the ethnic identity,

3. An evaluation of interactions of majority and minority.

The study used several methods of mathematical statistics: the mean (or average); the median and the mode (Mo), and, also, Pearson's r. Sample is normal and all the values fit into the general population characteristics.

\section{Results}

According to measures of central tendency, presented in the Table 2, values of all variables are conformed to the middle level. Data by the intercultural sensitivity are approximately equal, and what about is says? Analyzing, we should remember, that minimal number of marks corresponds to a greater intensity of variable. It means that low rates by the scale of acceptance indicate to high level of ethnorelativism, and low rates by the scale of minimization and absolutization indicate to high level of ethnocentrism. In our case, middle intensity of all scales could mean that intercultural sensitivity of respondents is on transitional stage of development. 
Summary table. Measures of central tendency

\begin{tabular}{|l|c|c|c|c|} 
& M & Mo & Me & level \\
\hline $\begin{array}{l}\text { Intercultural sensitivity: Acceptance } \\
\text { (ethno-ralativistic) }\end{array}$ & 40,40 & 40 & 40 & middle \\
\hline $\begin{array}{l}\text { Intercultural sensitivity: Minimization } \\
\text { (ethnocentric) }\end{array}$ & 40,47 & 33 & 40 & middle \\
\hline $\begin{array}{l}\text { Intercultural sensitivity: Absolutization } \\
\text { (ethnocentric) }\end{array}$ & 36,48 & 37 & 37 & middle \\
\hline $\begin{array}{l}\text { Intercultural sensitivity: Ambivalence } \\
\text { Locus of control }\end{array}$ & 27,21 & 30 & 27 & middle \\
\hline \begin{tabular}{l} 
Tolerance \\
\hline $\begin{array}{l}\text { Ethnic identity: } \\
\text { 1. A sense of belonging to the own } \\
\text { ethnic group, }\end{array}$
\end{tabular} & 21,02 & 21 & 21,5 & middle \\
$\begin{array}{l}\text { 2. A significance of the ethnic identity, } \\
\text { 3. An evaluation of interactions of } \\
\text { majority and minority. }\end{array}$ & 17,43 & 18 & 17 & middle \\
\hline \begin{tabular}{l} 
middle \\
\hline
\end{tabular} & 19,74 & 19 & 19,5 & middle
\end{tabular}

Index of the scales of locus of control, tolerance and ethnic identity are in the area of the middle significances too.

Using Pearson's r, some results were obtained. Statistically significant results are in Table 3.

\section{Significant correlations (Pearson's r)}

\begin{tabular}{|l|l|c|c|}
\multicolumn{1}{|c|}{ Variable 1 } & \multicolumn{1}{|c|}{ Variable 2 } & $\begin{array}{c}\text { Coefficient of } \\
\text { correlation }\end{array}$ & $\begin{array}{c}\text { Degrees of } \\
\text { freedom }\end{array}$ \\
\hline Acceptance & Tolerance & $\mathbf{0 , 2 3}$ & 0,05 \\
\hline Minimization & Tolerance & $\mathbf{0 , 3 4}$ & 0,01 \\
\hline Absolutization & Tolerance & $\mathbf{0 , 2 1}$ & 0,05 \\
\hline Absolutization & A significance of the ethnic identity & $\mathbf{- 0 , 3 1}$ & 0,025 \\
\hline Absolutization & $\begin{array}{l}\text { An evaluation of interactions of } \\
\text { majority and minority }\end{array}$ & $\mathbf{- 0 , 4 8}$ & 0,01 \\
\hline Ambivalence & $\begin{array}{l}\text { An evaluation of interactions of } \\
\text { majority and minority }\end{array}$ & $\mathbf{- 0 , 3 3}$ & 0,01
\end{tabular}

We can see the strongest connections $(\mathrm{p} \leq 0.01)$ there are between mininmization and tolerance, absolutization and evaluation of interactions of majority and minority, ambivalence and evaluation of interactions of majority and minority. Less strong links are between acceptance and tolerance $(\mathrm{p} \leq 0.05)$, absolutization 
and tolerance $(\mathrm{p} \leq 0.05)$, absolutization and a significance of the ethnic identity $(p \leq 0.025)$. At the same time, three correlation coefficients are showing to the backward connection:

- absolutization - a significance of the ethnic identity (- 0.31$)$;

- absolutization - an evaluation of interactions of ethnic majority and minority $(-0.48)$;

- ambivalence - an evaluation of interactions of ethnic majority and minority $(-0.33)$.

Other variables don't connect each other, at least, in our sample.

\section{Conclusion}

As we supposed, the intercultural sensitivity of respondents has developed on the middle level, which corresponds to the transition stage from ethnocentrism to ethnorelativism. It could be explained by the fact that the most of respondents hasn't many multicultural contacts in there daily life. That is why they needn't to develop their intercultural competence. In the other side, there aren't special events in the educational programs, directed to the growth of intercultural sensitivity. Perhaps it is not a problem now, but there is a likelihood that in the near future many of our respondents will had to work or help to people of different cultures and then some difficulties could be appear.

Indexes of locus of control, tolerance and ethnic identity, generally, corresponded to the norm. In other words, if there isn't social, political, economical or other crisis, most of population are characterized the middle level of tolerance, locus of control and ethnic identity. But our respondents are future specialists of humanitarian sphere that is why they should be more tolerant, more internal, and more competent in the ethnical questions.

There are connections between an intercultural sensitivity, a locus of control, a tolerance and an ethnic identity, as we thought. And quality of these connections is different. Really, only six of the twenty pairs of measured variables were statistically significant. According of these data there are sufficiently strong connections between intercultural sensitivity and tolerance, but a nature of the relationship is ambiguous. On the one hand, high level of tolerance corresponds to high level of ethnorelativistic attitudes, what we have supposed. On another hand, high level of tolerance corresponds to high level of ethnocentric attitudes and correlation is more reliable $(0,34$ against 0,23$)$. This result is unexpected. Is it possible that opinion about minimum significance of cultural differences in communication or confidence in the strong and no controlled influence of such differences to the educational or working processes could to coexist with respectful and considerate relations towards the other people. Why not? If we talk about common tolerance, not ethnic, all attitudes of intercultural sensitivity could be go together with it. 
The close negative correlation between absolutization and two components of ethnic identity is very interesting. One of them is a significance of the ethnic identity. According to our results, when a person attaches importance to its ethnic identity, he or she is not sure in uncontrollability of influence of cultural distinctions to the communication. Other of them is an evaluation of interactions of ethnic majority and minority. This interplay presupposes that the opinion about domination of ethnic majority above the ethnic minority stands against of opinion about total influence of cultural differences. Also, it stands against of ambivalence - conflicting attitudes combined with tendency of absolutization and conception about need to recognize them.

Our findings are contradictory and ambiguous. This once again indicates:

a) intercultural sensitivity is a complex phenomenon that requires of careful consideration;

b) the place of intercultural sensitivity among the other ethnic and cultural phenomena needs to be clarified;

c) there are questions about the significance of the level of development of intercultural sensitivity.

However, it is clear that tolerant person could be more attentive to the cultural distinctions and could choose the most right ways of interactions in the different situations. Intercultural sensitivity, definitely, is an important element of intercultural competence. It is necessary for each person who is going to work with people, especially if their work deals with multicultural groups. The educational organizations should to consider it and do accent on the development of intercultural competence and sensitivity at training of specialists. But without knowing of intercultural sensitivity's factors, we couldn't take account it.

Thereby could be important to examine connection between a professional effectiveness and intercultural sensitivity. Such study could give us the answer to a question: "is intercultural sensitivity as important in a structure of professional competences as we suppose?"

\section{References}

1. Bennett, M.J. (1993). Towards ethnorelativism: A developmental model of intercultural sensitivity. In R. Michael Paige (Ed.), Education for the intercultural experience. Yarmoth, ME: Intercultural Press.

2. Chibisova, M., Khukhlaev, O. (2008). Measuring teachers' intercultural competence: Towards a theory-based instrument. Book of Abstracts of the 19th International Congress of the International Association for Cross-Cultural Psychology, Germany, pp. 237-238

3. Lebedeva, N. (2011). Ethnic and cross-cultural psychology. Moscow: MAKS Press

4. Logashenko, Y.A. (2010). Value concepts "Intercultural Sensitivity" and "intercultural competence": Theoretical Problems of ethnic and cross-cultural psychology. Proceedings of the Second International Conference May 26-27, 2010. In 2 m. Ed. V.V. Gritsenko. Smolensk: pub. "Universe" - Vol.2. - 328p. 
5. Matsumoto, D. (2008). Man, culture, psychology. Amazing puzzles, exploration and discovery/ David Matsumoto. - St.: Prime - EVROZNAK - 668 p.

6. Oxford Dictionaries/ Definition of relativism. URL: http://www.oxforddictionaries.com/definition/english/relativism (March, 2014)

7. Pochebut, L.G. (2010). Socio-psychological principles of intercultural communication competence / Anan'evskij reading - 2010. Modern application trends and problems of psychology: Proceedings of the conference, 19-21 October 2010 Part 2 / Ed. Ed. LA Tsvetkov. - St.: Univ of St. Petersburg. Press - 592 p.

8. Pochebut, L. G. (2012). Cross-cultural and ethnic psychology. Saint Peterburg: Piter.

9. Romanova, O.L. (1994).Development of ethnic identity of children and youth: author's Ph.D. thesis, Moscow.

Dr. psych., professor

Ludmila Pochebut

Senior lecturer

Yuliya Logashenko
Department Professor in of Social Psychology St. Petersburg State University, Russia e-pasts: pochebut@rambler.ru

Department of Psychology and Social Work Immanuel Kant Baltic Federal University, Kaliningrad, Russia

e-pasts: ilogashenko@kantiana.ru 